Article

\title{
Anxiolytic, Antidepressant-Like Proprieties and Impact on the Memory of the Hydro-Ethanolic Extract of Origanum majorana L. on Mice
}

\author{
Amal Amaghnouje ${ }^{1}$, Hamza Mechchate ${ }^{1, *}{ }^{\oplus}$, Imane Es-safi ${ }^{1} \oplus$, Amal A. Alotaibi ${ }^{2}$, \\ Omar M. Noman ${ }^{3}{ }^{(1)}$, Fahd A. Nasr ${ }^{3}$ (D) Mohammed Al-zharani ${ }^{4}$, Pierfrancesco Cerruti ${ }^{5}$, \\ Anna Calarco ${ }^{6}{ }^{(0)}$, Hinde EL Fatemi ${ }^{7}$, Andriy Grafov ${ }^{8}$ and Dalila Bousta ${ }^{1}$ \\ 1 Laboratory of Biotechnology, Environment, Agrifood, and Health, \\ University of Sidi Mohamed Ben Abdellah, FSDM BP 1796-ATLAS, 30050 Fez, Morocco; \\ Amal.amaghnouje@usmba.ac.ma (A.A.); Imane.essafi1@usmba.ac.ma (I.E.-s.); \\ dalila.bousta@usmba.ac.ma (D.B.) \\ 2 Basic Science Department, College of Medicine, Princess Nourah Bint Abdulrahman \\ University, Riyadh 11671, Saudi Arabia; amaalotaibi@pnu.edu.sa \\ 3 Medicinal Aromatic, and Poisonous Plants Research Centre, College of Pharmacy, King Saud University, \\ Riyadh 11451, Saudi Arabia; Onoman@ksu.edu.sa (O.M.N.); Fnasr@ksu.edu.sa (F.A.N.) \\ 4 Biology Department, College of Science, Imam Mohammad Ibn Saud Islamic University (IMSIU), \\ Riyadh 11623, Saudi Arabia; MMyAlzahrani@imamu.edu.sa \\ 5 Institute for Polymers, Composites, and Biomaterials (IPCB-CNR), via Campi Flegrei 34, \\ 80078 Pozzuoli (NA), Italy; cerruti@ipcb.cnr.it \\ 6 Research Institute on Terrestrial Ecosystems (IRET), National Research Council, 05010 Porano, Italy; \\ anna.calarco@cnr.it \\ 7 Departments of Pathology, University Hospital Hassan II, 30050 Fez, Morocco; Elfatemihinde@gmail.com \\ 8 Department of Chemistry, University of Helsinki, 00560 Helsinki, Finland; anriy.grafov@helsinki.fi \\ * Correspondence: hamza.mechchate@usmba.ac.ma; Tel.: +212-602-083-601
}

Received: 1 November 2020; Accepted: 24 November 2020; Published: 26 November 2020

\begin{abstract}
Marjoram (Origanum majorana L.) infusion has been used as folk medicine against depression and anxiety. However, no studies have been carried out yet to prove those activities scientifically. In this study, the anxiolytic, antidepressant-like effects, and memory impact of the hydro-ethanolic extracts of marjoram were evaluated in mice. The hydro-ethanolic extracts ( 250 and $500 \mathrm{mg} / \mathrm{kg}$ ) were evaluated for their central nervous effect using six different behavioral tests such as light-dark box (LDB) and open field (OF) for anxiety, forced swim test (FST), and tail suspension test (TST) for depression, and object recognition test (ORT), Morris water maze (MWM) for the impact on memory. The experiments were realized on days $1,7,14$, and 21 of treatments and compared with bromazepam for anxiety $(1 \mathrm{mg} / \mathrm{kg})$ and paroxetine for depression $(11.5 \mathrm{mg} / \mathrm{kg})$. The phytochemical screening was performed by HPLC, and the acute and sub-acute toxicities were performed following OCED guidelines $\left(\mathrm{N}^{\circ} 423\right.$ and 407$)$ with biochemical parameters evaluation and histopathological analysis. Oral administration of marjoram hydro-ethanolic extract induced significant anxiolytic and antidepressant-like effects without memory impairment, increasing the exploration and time spent in the light area in the LDB test in a similar way to that of bromazepam. In the FST and TST, the extract was as effective as paroxetine $(11.5 \mathrm{mg} / \mathrm{kg}$, p.o.) in reducing immobility. The phytochemical screening showed the presence of ferulic acid, naringin, hydroxytyrosol, geraniol, and quercetin. This study approves the traditional use of this plant and encourages further investigation on its bioactive compounds.
\end{abstract}


Keywords: anxiolytic; antidepressant; memory impact; Origanum majorana L.; OECD 423, 407; light-dark box test; Morris water maze test; object recognition test; open field test; forced swim test; tail suspension test

\section{Introduction}

Anxiety and depression are heterogeneous, complicated psychological illnesses and one of the world's leading causes of impairments [1]. Anxiety is the body's natural response to stress, and it's mainly treated with benzodiazepines (BZs). BZs consumption with time induces anterograde amnesia, and they alter the capacity to recognize and recall information regulated by the gamma-aminobutyric acid (GABAA) receptor [1]. It is much less likely that the action of BZs entails more complex modifications in the synaptic transmission of the hippocampus [2]. While depression is a mood disorder that can interfere with everyday functioning, triggering a constant sense of sadness and lack of interest, caused by an imbalance in the monoamine neurotransmitters serotonergic, noradrenergic, and/or dopaminergic systems, treatments are diverse, but the adverse effects still discouraging people from adhering to them [3]. Lately, medical plants show real potential as an alternative and safe therapy for many disorders, and it may be effective as well in the treatment of depression and anxiety without side effects [4]. Plants and spices contain a wide array of phytochemicals with strong pharmacological and biological properties [5]. One of these plants is marjoram, an aromatic herb widely used as a spice and condiment. Its volatile oil is used in cosmetics and vermouth and historically as a stimulant and a tonic as a medicinal herb [6]. Different pharmacological activities have been attributed to this plant, including antioxidant [7], antibacterial [8], anti-inflammatory [9], cardioprotective, hepatoprotective [9], antiulcerogenic [10], anticancer and antiproliferative activities [11]. This study was undertaken to evaluate the antidepressant-like and anxiolytic activity and the effect of this plant on memory using six different tests: forced swimming test (FST), tail suspension test (TST), open field test (OFT), light-dark box test (LDB), Morris water maze (MWM), and novel object recognition (NOR) tests.

Bromazepam is a drug commonly used to treat severe anxiety. Its consumption comes with multiple side effects reported such as drowsiness, sedation, memory impairment [12]. While paroxetine is an antidepressant of the SSRI class (serotonin reuptake inhibitors) used to treat major depressive disorder, its common side effects include drowsiness, dry mouth, loss of appetite, sweating, trouble sleeping, and sexual dysfunction [13]. To compare the effect of this plant, both drugs were used as a positive control. The phytochemical composition responsible for the plant effect was identified using HPLC.

\section{Materials and Methods}

\subsection{Plant}

The leaves of marjoram (Origanum majorana L.) were collected from the region of Rissani in the south of Morocco. The plant was identified and authenticated by botanist Amina Bari from the Laboratory of Biotechnology and Conservation of Natural Resources in the Faculty of Science Dhar El Mahraz, Fez. A voucher specimen (DACB: BPRN74) has been deposited in the Herbarium for further reference.

\subsection{Hydro-Ethanolic Extract Preparation}

The hydro-ethanolic extract of the marjoram was obtained by ultrasound sonication. Twenty grams of dried plant powder (obtained using an electric grinder (KRUPS; GX332850; Solingen, Germany)) was put in a flask with $200 \mathrm{~mL}$ of ethanol-water (70/30) and then immersed in the ultrasonic bath (HINOTEK; SB-100DT; Ningbo, China) at a frequency of $35 \mathrm{kHz}$ for $45 \mathrm{~min}$. Then, the extract was 
filtered (Whatman paper), concentrated (rotary evaporator (BUCHI; R-100 Rotavapor ${ }^{\circledR}$; New Castle, DE, USA), and conserved for further use.

\subsection{Animals}

Swiss albino mice weighing approximately $25-35 \mathrm{~g}$ were used for the different tests. They were housed in polypropylene cages in an air-conditioned room, with a temperature maintained at $24 \pm 2{ }^{\circ} \mathrm{C}$ with free access to food and water.

Mice were randomly assigned to treatment groups ( $n=7-8 /$ treatment). Two doses of the plant extract were tested $(250$ and $500 \mathrm{mg} / \mathrm{kg}$ ). Bromazepam was used as a positive control for anxiety tests at $1 \mathrm{mg} / \mathrm{kg}$ and paroxetine for the depression tests at $11.5 \mathrm{mg} / \mathrm{kg}$. The groups received a subacute treatment for 21 days, and they were tested on the 1st, 7th, 14th, and 21st day, except for the MWM test where the mice received continuous treatment for 21 days, and they were tested on the five next days. Animals were transferred from their cages to the experimental room and allowed to be habituated for at least one hour before the beginning of the behavioral tests. Testing was performed in a randomized order during the animal's active period ( 6 a.m. -6 p.m.). The treatments were given orally to the animals by intragastric gavage using a stainless-steel bulb tipped gavage needle in order to deliver it into the stomach. Preliminary tests were performed to choose the lowest effective doses to conduct the study with $(250$ and $500 \mathrm{mg} / \mathrm{kg}$ ). The institutional animal ethical committee approved the protocol (09/2019/LBEAS).

\subsection{Antidepression Tests}

\subsubsection{Forced Swimming Test}

The FST was originally described by Elhwuegi [14] and is one of the most widely used pharmacological tests for assessing antidepressant-like activity [15]. The animal is maintained in a rectangular pool $(50 \times 30 \times 60 \mathrm{~cm})$, filled to a $25 \mathrm{~cm}$ depth with water at room temperature at $22-25^{\circ} \mathrm{C}$ [16]. The test is based on the assumption that the animal will swim actively in order to escape from stressful stimuli. The total duration of immobility was recorded during 4 min of the total test duration of $6 \mathrm{~min}$ [17].

\subsubsection{Tail Suspension Test}

In a box $(50 \times 25 \times 50 \mathrm{~cm})$, the animal was hung by the tail $(2 \mathrm{~cm}$ away from the end of the box $)$ for $6 \mathrm{~min}$. The immobility time (depressive behavior) was recorded for only the last $4 \mathrm{~min}$ when the animal fails to make any struggling movement and hung with passivity without motions [18].

\subsection{Anxiety Tests}

\subsubsection{Open Field Test}

This test was performed in a wooden apparatus divided into 25 equal squares $(45 \mathrm{~cm} \times 45 \mathrm{~cm} \times 13 \mathrm{~cm})$. Assisted with a digital video camera, the number of ambulations, rearings, and central square crosses were recorded after putting each mouse in the center square as a starting point $[19,20]$.

Ambulation indicates the sum of total squares crossed by the mouse. When a mouse crosses a square with four paws, it is counted as a square number, and for central squares, it is noted as central square crossing [21,22].

\subsubsection{Light-Dark Box Test}

The apparatus consisted of two wooden boxes $(44 \mathrm{~cm} \times 21 \mathrm{~cm} \times 21 \mathrm{~cm})$ : one was dark, and the other was white. The two compartments were divided by a wooden blank, with a $7 \mathrm{~cm} \times 7 \mathrm{~cm}$ opening 
in the middle on the floor surface. A $100 \mathrm{~W}$ bulb was placed $30 \mathrm{~cm}$ above the floor of the white box (the only light source in the room). Mice were tested in $5 \mathrm{~min}$ [23].

The time spent in the light area, the number of crossing between two compartments [24]. The apparatus after each use was cleaned to get rid of any odor or leftovers that may disturb the mouse on the next experiment.

\subsection{Memory Tests}

\subsubsection{Morris Water Maze}

This test is used for the evaluation of spatial learning and memory. The pool was filled with water $\left(24-25^{\circ} \mathrm{C}\right)$. During the training days, each mouse was released on the surface of the water from one of the four directions (north, east, south, and west) and was allowed to swim to look for the round hidden platform for $1 \mathrm{~min}$. The time latency to find the platform was recorded via a digital video camera. The mice that failed to find the platform were conducted by the experimenter to it and permitted to stay $10 \mathrm{~s}$ on the platform [25]. The experiments were replicated every day for five straight days. The platform was removed on day 6, the animals were allowed to swim for $60 \mathrm{~s}$ and the time spent, distance traveled was measured in the target quadrant.

\subsubsection{Novel Object Recognition Test}

This test was conducted in an open square box with the following dimensions: $52 \times 52 \times 25 \mathrm{~cm}$. The objects to be discriminated were in two different shapes. The test period consists of a habitation period, an acquisition period, and a test trial.

Habitation day is the day before the experiment, during it, the mouse was placed in the box (empty) for $2 \mathrm{~min}$.

During the 1st trial, the mice were allowed to explore in the open-field box in which two identical objects: the familiar objects $(F+F)$, were placed for $5 \mathrm{~min}, 10 \mathrm{~cm}$ from the sidewall. The mouse was allowed to explore the objects after been placed in the middle of the box. During the 2nd trial, one of the two objects was replaced by a novel one $(\mathrm{N})$, and the mice were allowed to explore in the open-field apparatus for $5 \mathrm{~min}$.

Turning around or sitting on the object was not considered as exploratory behavior. The exploration was defined as follows: directing the nose toward the object at a distance of no more than $2 \mathrm{~cm}$ and/or touching the object with the nose.

The time spent with the exploration of each object during 1st and 2nd trial tests were recorded [25].

\subsection{Acute and Sub-Acute Toxicity Studies}

\subsubsection{Acute Toxicity}

The oral acute toxicity study of the hydroethanolic extract of Origanum majorana L. was evaluated according to the Organization for Economic Cooperation and Development (OECD) guideline number 423 , using male and female mice. The dose tested was $2 \mathrm{~g} / \mathrm{kg}$. The groups were observed closely for any toxic effect (changes in skin, hair, eyes, mucous membranes, and respiratory, circulatory, autonomic, and central nervous) within the first hour and then at regular intervals for a total period of 14 days.

\subsubsection{Sub-Acute Toxicity Test}

This study was performed according to OECD guidelines 407. Animals were divided into three groups of 5 mice. Groups II-III received 250 and $500 \mathrm{mg} / \mathrm{kg}$ of the extract, respectively, while group I received $\mathrm{Nacl} 0.9 \%(5 \mathrm{~mL} / \mathrm{kg})$ only for 28 days.

Biochemical parameters (urea, creatinine, alanine aminotransferase (ALT), aspartate aminotransferase (AST), alkaline phosphate) were measured by using Randox kits at the end of the test. 


\subsection{Extract HPLC Analysis}

High-performance liquid chromatography (Agilent Technologies 1260 infinity II) was used to perform the analysis on the hydro-ethanolic extract of $O$. majorana. The apparatus was equipped with a quaternary pump and coupled with a UV detector. The mobile phase consisted of two solvents, A: acidified water $0.1 \%$ and B: acetonitrile. The column used for the separation was a C18 zorbax eclipse plus $\mathrm{C} 18(5 \mu \mathrm{m}, 4.6 \times 150 \mathrm{~mm})$. The column furnace temperature was fixed at $35^{\circ} \mathrm{C}$. The sample injection volume and flow rates were $10 \mathrm{~mL}$ and $1 \mathrm{~mL} / \mathrm{min}$, respectively. The concentration was calculated on the basis of the retention time (RT) and spectral correspondence of each compound according to the following equation:

Concentration $(\mu \mathrm{g} / \mathrm{mL})=($ Area noted for the sample/area noted for the standard $) \times 100$.

\subsection{Histological Examination}

At the end of the treatment, the animals were sacrificed, and organs, liver, and kidneys were removed for histological examinations. All organs were immediately fixed in $10 \%$ buffered formalin, and then the histological cuts were prepared: namely fixation, dehydration, paraffin embedding, microtome sections, and coloration with a hematoxylin-eosin-safran (HES). Finally, the cuts were observed by an optical microscope.

\subsection{Statistical Analysis}

All results were expressed as mean \pm standard error of the mean (SEM) and analyzed using Graph Pad Prism 7 Software. The data analysis was carried out using a two-way analysis of variance (ANOVA). Dunnett test was used for comparisons between all columns and normal control. Results were considered significant when $p<0.05$.

\section{Results}

\subsection{Tail Suspension Test}

As shown in Figure 1, immobility time in TST revealed significant differences F $(9,80)=4,93$; $p<0.001$. Post hoc analysis by Dunnett test showed that hydro-ethanolic extract of marjoram (250 and $500 \mathrm{mg} / \mathrm{kg})$ and paroxetine $(11.5 \mathrm{mg} / \mathrm{kg})$ significantly decreased $(p<0.001)$ the immobility time as compared to the normal control.

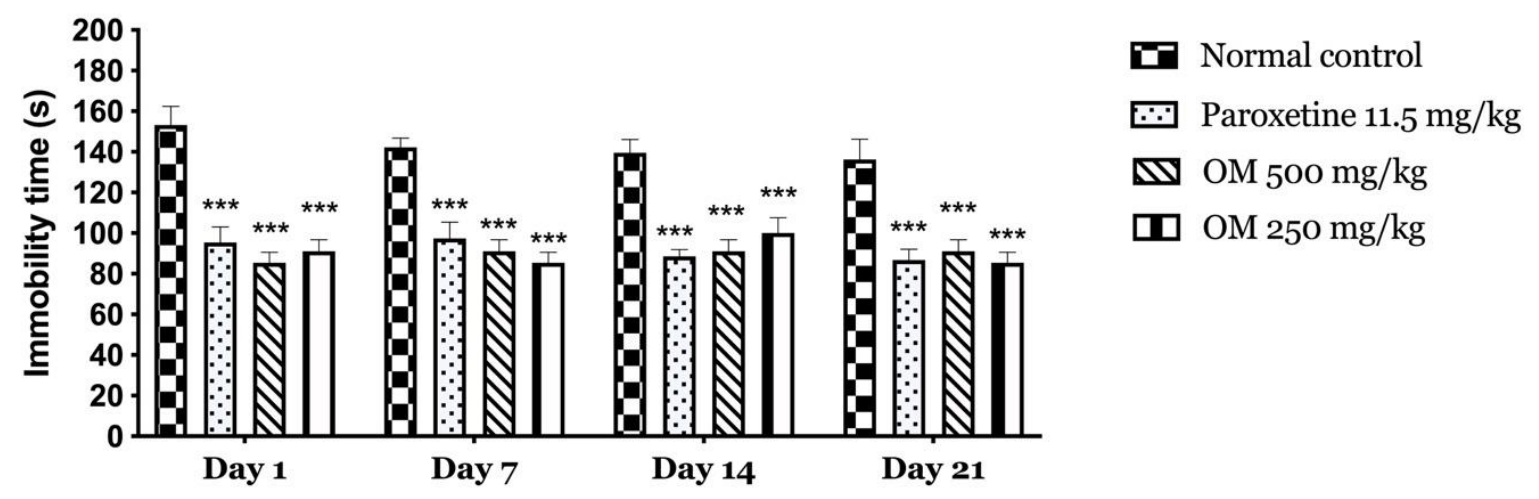

Figure 1. Effects of OM (O. majorana) on the Tail Suspension Test in mice on the 1st, 7th, 14th, and 21st days. Values are expressed as mean \pm SEM. The analysis was done using two-way repeated-measures analysis of variance followed by Dunnett post hoc test ${ }^{* * *} p<0.001$, compared with normal control. 


\subsection{Forced Swimming Test}

The analysis of the immobility time in the FST test revealed significant differences, $\mathrm{F}(9,80)=14,57$ $p<0.001$. The post hoc test showed a significant difference compared with normal control for all groups $(p<0.001)$ in the 14th and 21st days of the test. However, after the 7th day, the results indicate similar activity of both plant extract doses compared with paroxetine (Figure 2).

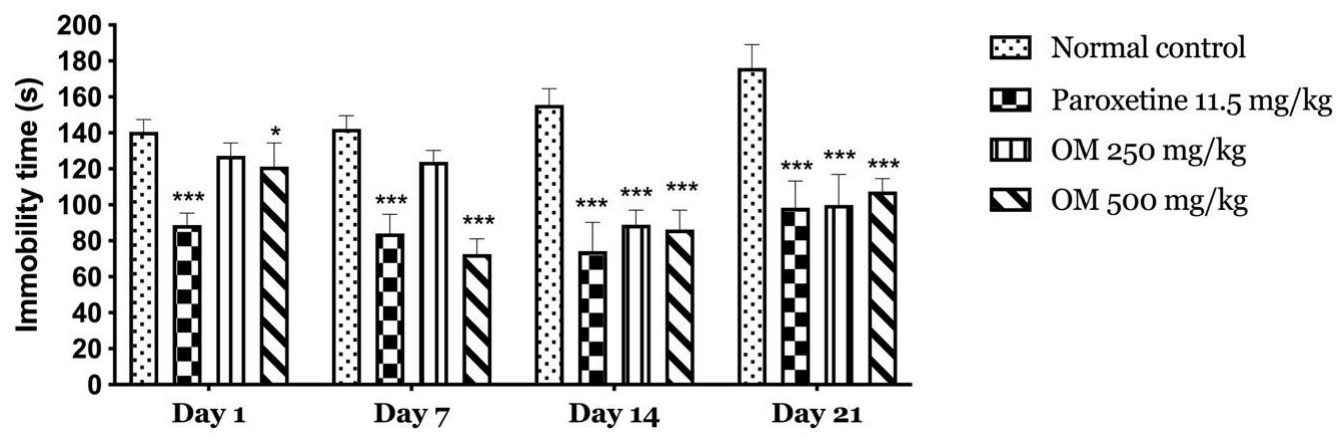

Figure 2. Effects of OM on the Forced Swimin Test test in mice on the 1st, 7th, 14th, and 21st days. Values are expressed as mean \pm SEM. The analysis was done using two-way repeated-measures analysis of variance followed by Dunnett post hoc test ${ }^{* * *} p<0.001,{ }^{*} p<0.05$ compared with normal control.

\subsection{Open Field Test}

The analysis of the number of total squares crossing revealed significant differences $F(9,80)=4,711$; $p<0.001$. The post hoc test showed that after the seventh day of the treatment, the bromazepam group significantly decreased the number of total squares crossed $(p<0.001)$ (Figure $3 \mathrm{~A})$.

A)

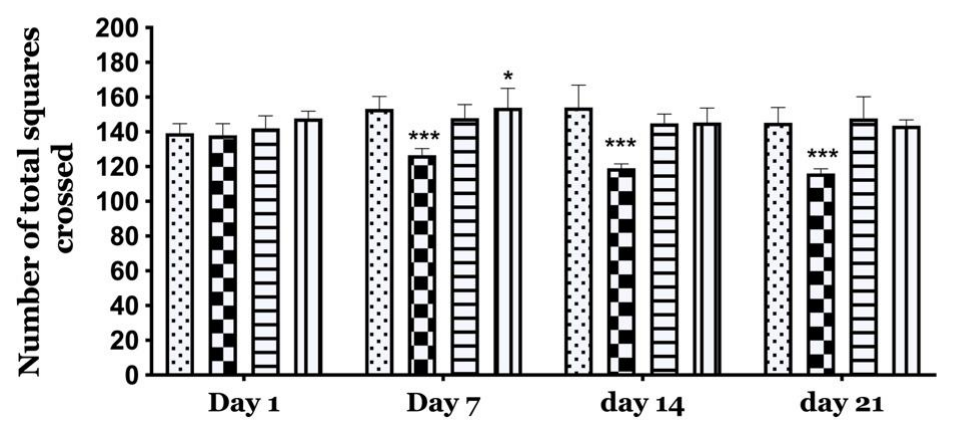

Normal control

[D. Bromazepam $1 \mathrm{mg} / \mathrm{kg}$

曰 $\mathrm{OM}_{500 \mathrm{mg}} / \mathrm{kg}$

미 OM $250 \mathrm{mg} / \mathrm{kg}$

B)

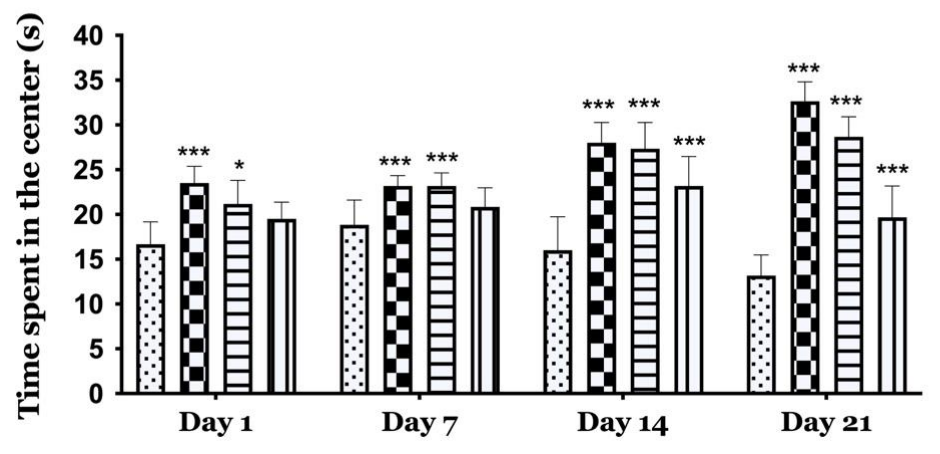

$\because$ Normal control

므 Bromazepam $1 \mathrm{mg} / \mathrm{kg}$

曰 $\mathrm{OM}_{500 \mathrm{mg} / \mathrm{kg}}$

미 OM $250 \mathrm{mg} / \mathrm{kg}$

Figure 3. Temporal effects of OM in the open field test. (A) Number of total squares crossed (B) time spent in the center. Values are expressed as mean \pm SEM. The analysis was done using two-way repeated-measures analysis of variance followed by Dunnett post hoc test ${ }^{* * *} p<0.001,{ }^{*} p<0.05$ compared with normal control. 
Statistical analysis of the time spent in the center revealed a significant increase in all periods of the treatment, $F(9,80)=9,247 p<0.001$. Post hoc test revealed that mice treated with OM $500 \mathrm{mg} / \mathrm{kg}$ had spent a high time in the center compared to the normal control. OM $250 \mathrm{mg} / \mathrm{kg}$ was not significant until the 14th day (Figure 3B).

\subsection{Light-Dark Box Test}

Statistical analysis of the number of transitions revealed a significant increase $F(9,80)=5,56$ $p<0.001$. Post hoc test revealed that mice treated with OM $500 \mathrm{mg} / \mathrm{kg}$ had a high number of transitions between two compartments compared to the normal group. OM $250 \mathrm{mg} / \mathrm{kg}$ was not significant compared with the normal group (Figure $4 \mathrm{~A}$ ).

A)

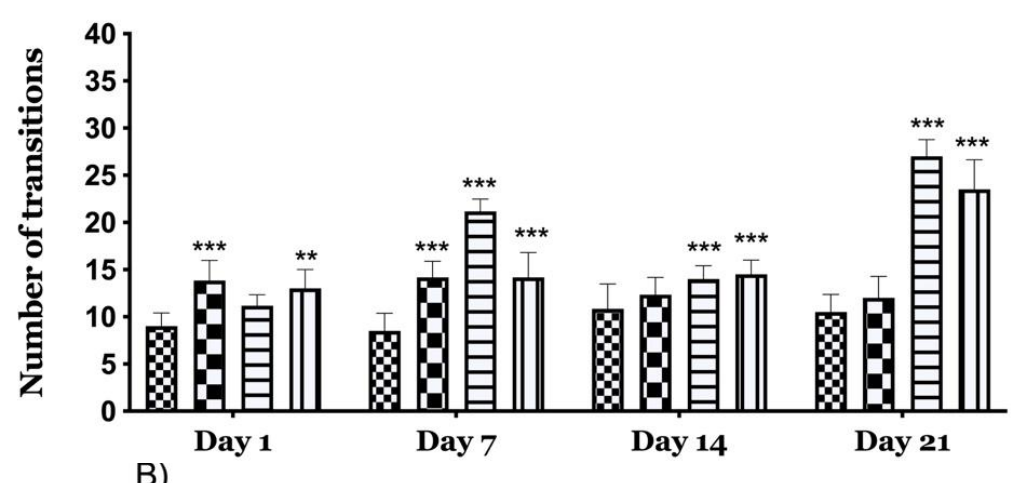

W Normal control

D. Bromazepam $1 \mathrm{mg} / \mathrm{kg}$

曰 OM $250 \mathrm{mg} / \mathrm{kg}$

س $\mathrm{OM} 500 \mathrm{mg} / \mathrm{kg}$

B)

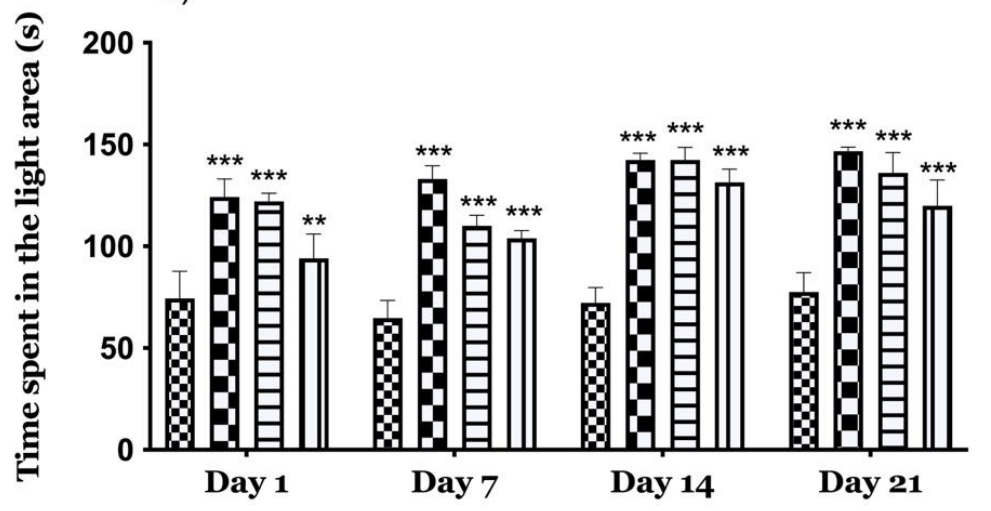

W Normal control

므 Bromazepam $1 \mathrm{mg} / \mathrm{kg}$

曰 $\mathrm{OM}_{5} 00 \mathrm{mg} / \mathrm{kg}$

س $\mathrm{OM} 250 \mathrm{mg} / \mathrm{kg}$

Figure 4. Temporal effects of OM in the light/dark box test (A) the number of transitions between the dark and light compartment (B) Time spent in the light area. Values are expressed as mean \pm SEM. The analysis was done using two-way repeated-measures analysis of variance followed by Dunnett post hoc test ${ }^{* * *} p<0.001,{ }^{* *} p<0.01$ compared with normal control.

The analysis of the results of the Light-dark box test revealed a significant increase in the time spend in the light area $F(9,80)=22,61 ; p<0.001$. The post hoc test showed a significant effect of OM at different doses compared to the normal group (Figure 4B).

\subsection{Morris Water Maze (MWM)}

The analysis of the time latency to find the platform has significant differences between the first, second, third, and fourth days. F $(9,80)=41,07 ; p<0.001$. Post hoc test revealed that the latency time of mice treated with $\mathrm{OM}(250$ and $500 \mathrm{mg} / \mathrm{kg}$ ), and normal control, decreases from the first to the fourth day. For bromazepam, no difference was noted during the trial period in latency time (Figure 5A). 

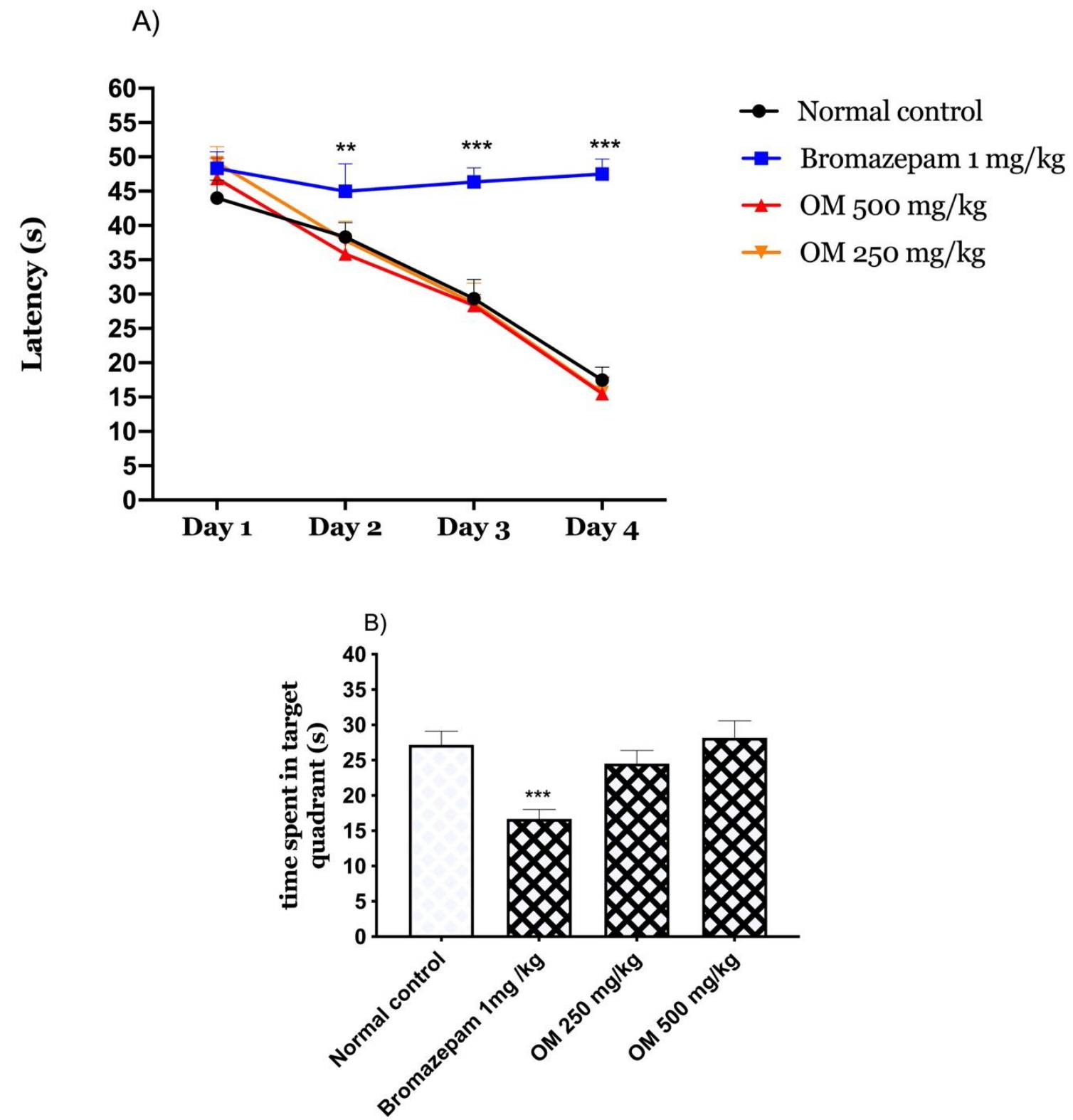

Figure 5. Effects of $\mathrm{OM}$ in the Morris water maze test. (A) latency time, (B) time spent in the target quadrant. Values are expressed as mean \pm SEM. The analysis was done using two-way repeated-measures analysis of variance followed by Dunnett post hoc test ${ }^{* * *} p<0.001,{ }^{* *} p<0.01$ compared with normal control.

On day 5 , the target quadrant in respect to the other quadrants was noted as an index of retrieval memory. Th bromazepam group significantly spent less time in the correct quadrant compared to the control group in the probe trail $(\mathrm{F}(5,30)=11,19 ; p<0.001)$, while the group treated with the dose of $500 \mathrm{mg} / \mathrm{kg}$ increased the swimming time in the target quadrant (Figure $5 \mathrm{~B}$ ).

\subsection{Novel Object Recognition Test}

During the training period, the bromazepam group spends less time exploring the objects, unlike OM (250 and $500 \mathrm{mg} / \mathrm{kg})$, which spent more time compared to the normal group. During the test period, the groups treated with OM $(250$ and $500 \mathrm{mg} / \mathrm{kg})$ showed a significant increase in time spent exploring the novel object $\mathrm{F}(3,40)=1,389, p=0.2600$. The administration of bromazepam significantly decreased the time spent exploring novel objects $(p<0.01)$ (Figure 6). 


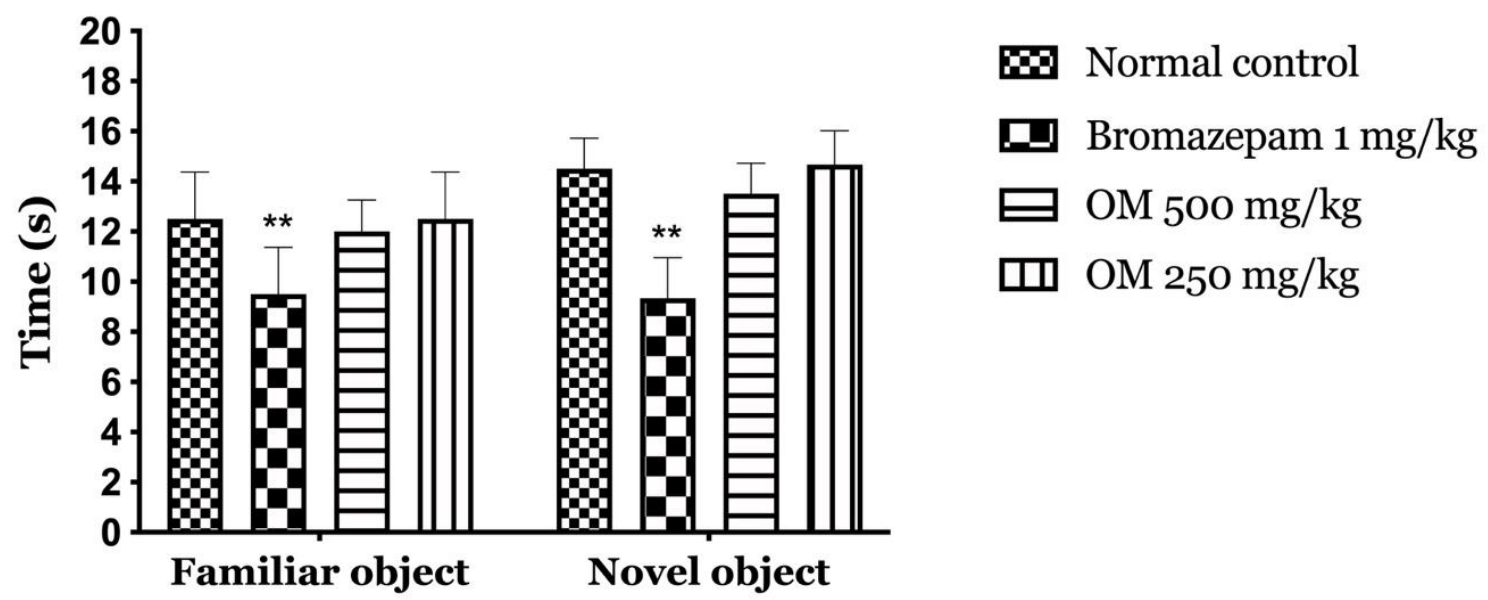

Figure 6. Novel object recognition test effect of OM on the memory object recognition test. Values are expressed as mean \pm SEM. The analysis was done using two-way repeated-measures analysis of variance followed by Dunnett post hoc test ${ }^{* *} p<0.01$ compared with normal control.

\subsection{Toxicity Studies}

\subsubsection{Acute Oral Toxicity Study}

In the acute toxicity study, the oral administration of a single dose up to $2 \mathrm{~g} / \mathrm{kg}$ did not exhibit any mortality or toxicity signs during the 14 days. No significant changes in body weight development were detected. Therefore, the lethal dose (LD50) of marjoram extract was not estimated because no mortality was detected.

\subsubsection{Sub-Acute Oral Toxicity Study}

The administration of marjoram for 28 consecutive days did not induce behavioral changes in treated mice compared to the control group. No mortality or sign of toxicity or alteration in normal bodyweight development was noted during 28 days. There was no significant effect on relative organ weight in treated and control groups (Table 1).

Table 1. Effect of sub-acute administration of OM on the relative weight of organs.

\begin{tabular}{cccc}
\hline & Normal Control & OM 500 & OM 250 \\
\hline Liver & $8.95 \pm 0.73$ & $7.58 \pm 0.56$ & $7.60 \pm 0.97$ \\
Kidney & $1.79 \pm 0.24$ & $1.39 \pm 0.212$ & $1.35 \pm 0.16$ \\
Spleen & $0.74 \pm 0.63$ & $0.62 \pm 0.79$ & $0.68 \pm 0.15$ \\
\hline \multicolumn{4}{c}{ Values are expressed as mean \pm SEM. }
\end{tabular}

The effects of sub-acute administration of marjoram on biochemical parameters are present in Table 2. Repeated administration of OM for 28 days did not alter the normal biochemical parameters of the mice.

Table 2. Effect of sub-acute administration of OM on biochemical parameters in male mice $(n=5)$.

\begin{tabular}{cccc}
\hline & Normal Control & OM $250 \mathbf{~ m g} / \mathbf{k g}$ & OM $500 \mathbf{~ m g} / \mathbf{k g}$ \\
\hline UREA & $0.28 \pm 0.02$ & $0.26 \pm 0.01$ & $0.27 \pm 0.017$ \\
CREATININE & $3.40 \pm 0.31$ & $4 \pm 0.6$ & $3.333 \pm 0.33$ \\
ALT & $36.80 \pm 1.11$ & $22.33 \pm 1.2 *$ & $32.12 \pm 0.57$ \\
AST & $307.7 \pm 30.37$ & $311 \pm 65.68$ & $344.7 \pm 23.85$ \\
\hline
\end{tabular}

Values are expressed as mean \pm SEM., ${ }^{*} p<0.01$. 


\subsection{Extract Biochemical Analysis}

The chromatogram of the HPLC analysis is shown in Figure 7, revealing the main compounds: ferulic acid, naringin, hydroxytyrosol, geraniol, and quercetin, detailed in Table 3.

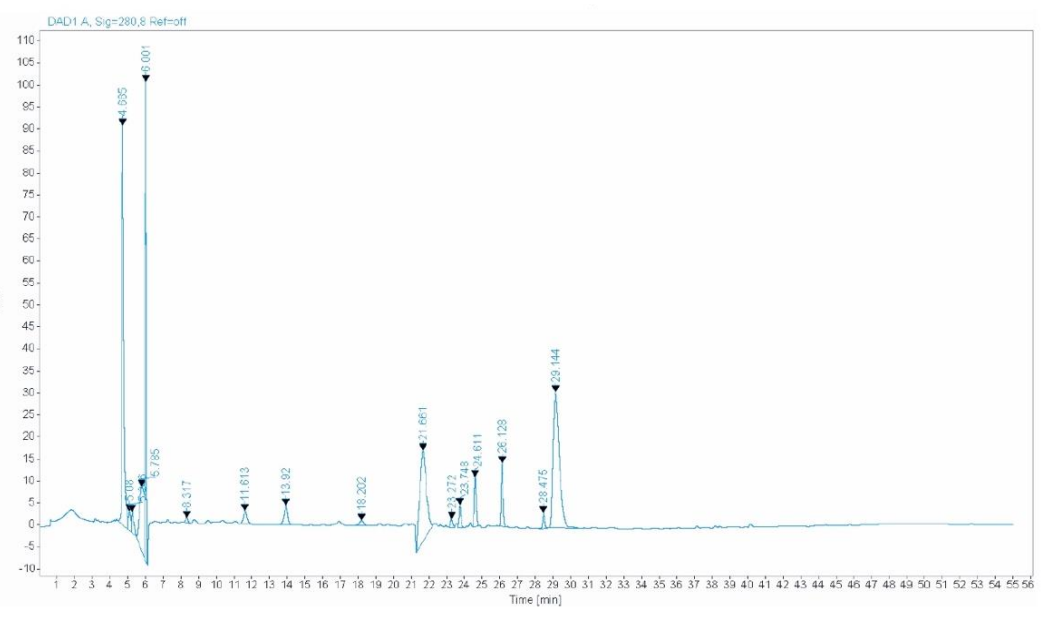

Figure 7. The HPLC chromatogram of OM hydro-ethanolic extract.

Table 3. The HPLC result of OM hydro-ethanolic extract.

\begin{tabular}{ccccc}
\hline \multirow{2}{*}{ Extract } & Molecules & Standard & Retention & \multicolumn{2}{c}{ Concentration } \\
& & Retention Time & Time & 198.22 \\
& Ferulic acid & 21.630 & 21.661 & 11.66 \\
Hydroethanolic extract & Naringin & 24.634 & 24.611 & 8.28 \\
Origanum majorana L. & Hydroxytyrosol & 8.555 & 8.317 & 3.08 \\
& Geraniol & 28.561 & 28.475 & 3.06 \\
\hline
\end{tabular}

\subsection{Histological Examination}

After checking the microscopic sections of the liver and kidney of the normal control and the extract at both doses, no pathological lesions were noticed, and the sections indicate only normal histology (Figure 8).

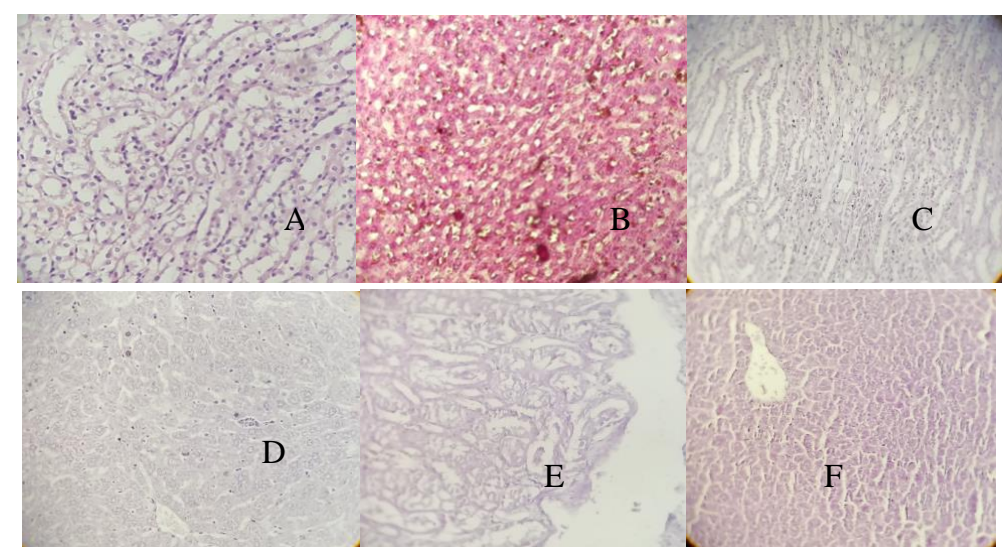

Figure 8. Histopathological examination of various organs of the mouse in oral toxicity study; $(\mathbf{A}, \mathbf{B})$ are liver and kidneys of the control group; (C,D) are kidney and liver of the group treated with OM at the dose of $250 \mathrm{mg} / \mathrm{kg}$. (E,F) are kidney and liver of the group treated with OM at the dose of $500 \mathrm{mg} / \mathrm{kg}$. (A and B) normal cells (C) normal cells (D and F), respectively, showing a normal arrangement of hepatocytes, mild inflammation, normal histological architecture with the central vein (E) shows some tubular degeneration (haematoxylin and heosin, $(\mathrm{H} \& \mathrm{E}) \times 400)$. 


\section{Discussion}

Marjoram has been used for the relief of anxiety in Moroccan folk medicine. The anxiolytic and antidepressant activities and the effects on memory of the OM extract ( 250 and $500 \mathrm{mg} / \mathrm{kg}$ ) were examined in mice using multiple tests to confirm their proprieties. OFT and LDB are currently two of the most widely used tests to study animal anxiety and has been validated for use with mice. For the OFT, the more time the animal spends hugging the walls, the more anxious it probably is. Exploring the middle of the arena and how long it takes for the animal to start doing so is seen as an indicator of exploration or boldness. In the LDB test, the mice prefer darker environments over lighter ones. However, when placed in a novel place, rodents prefer to investigate. These two contrasting feelings contribute to visible anxiety-like signs [26]. When animals are injected with anxiolytic products, the percentage of time spent in the light compartment can increase. The anxiolytic effect of marjoram was proved by the test and was in accordance with previous research on the essential oil fraction of the plant [27].

The FST and TST are the most widely used tests for antidepressant-like activity screening in mice. In these tests, the index of despair and depression was the immobility behavior [28]. Our findings suggest besides the antidepressant-like activity of the extract, a dose-effect relation was noted as the effect was better with the highest dose $(500 \mathrm{mg} / \mathrm{kg})$.

MWM is used to evaluate the effect of drugs on memory. In this context, our findings showed that OM (250-500 mg/kg) had no significant effect on memory compared to bromazepam known to induce memory impairment after chronic treatment. Furthermore, the extract did not induce any changes in spontaneous locomotors. While on the ORT, the time required to discover the new object in the second session did not indicate any memory impairment.

The high-performance liquid chromatography reported the presence of ferulic acid, naringin, hydroxytyrosol, geraniol in the hydro-ethanolic extract. Some studies showed the antidepressant effect of ferulic acid in mice [29] and the anxiolytic effect of hydroxytyrosol [30].

In other studies, enhancement of 5-HT and NE levels in polyphenol-treated animals can complement the observed antidepressant effect. In addition, these neurotransmitters have been involved in the expression of antidepressant effect in behavioral despair tests of depression as described by Detke et al. [3,31]. The antidepressant drugs enhanced swimming act through serotonergic neurotransmission (paroxetine) and catecholaminergic neurotransmission (desipramine) [32]. In the current study, our results showed enhanced swimming time in animals treated with OM, indicating that the effect can be mediated through both serotonergic and catecholaminergic neurotransmissions.

\section{Conclusions}

Different tests were conducted in this study to confirm the traditional proprieties of this plant treating anxiety and depression without impact on the memory, which was one of the most dangerous side effects of using classic drugs. Marjoram at both doses, 250 and $500 \mathrm{mg} / \mathrm{kg}$, exhibited remarkable activity with sometimes a dose-related effect, suggesting that the dose of $500 \mathrm{mg} / \mathrm{kg}$ had the best effect. The extract showed no effect on the memory, suggesting that it may be a real alternative to classic drugs, taking into consideration also its complete safety after the acute and subacute toxicity study. In light of those results, this plant deserves further investigations to isolate the component responsible for the effect and determine its mechanism of action.

Author Contributions: Conceptualization, A.A. and D.B.; methodology, H.M.; software, I.E.-s.; validation, P.C. and A.G.; formal analysis, A.C. and H.E.F.; data curation, I.E.-s.; writing-original draft preparation, A.A. and H.M.; writing-review and editing, O.M.N. and F.A.N.; supervision, D.B.; funding acquisition, A.A.A. and M.A.-Z. All authors have read and agreed to the published version of the manuscript.

Funding: This research was funded by the Deanship of Scientific Research at Princess Nourah bint Abdulrahman University through the Fast-track Research Funding Program.

Acknowledgments: The authors extend their appreciation to the Deanship of Scientific Research at Princess Nourah bint Abdulrahman University for funding this work through the Fast-track Research Funding Program. 
Conflicts of Interest: The authors declare no conflict of interest.

\section{References}

1. Griffin, C.E.; Kaye, A.M.; Bueno, F.R.; Kaye, A.D. Benzodiazepine pharmacology and central nervous system-mediated effects. Ochsner J. 2013, 13, 214-223. [PubMed]

2. Luscher, C.; Malenka, R.C. NMDA Receptor-Dependent Long-Term Potentiation and Long-Term Depression (LTP/LTD). Cold Spring Harb. Perspect. Biol. 2012, 4, a005710. [CrossRef] [PubMed]

3. Elhwuegi, A.S. Central monoamines and their role in major depression. Prog. Neuropsychopharmacol. Biol. Psychiatry 2004, 28, 435-451. [CrossRef]

4. Es-Safi, I.; Mechchate, H.; Amaghnouje, A.; El Moussaoui, A.; Cerruti, P.; Avella, M.; Grafov, A.; Bousta, D. Marketing and legal status of phytomedicines and food supplements in Morocco. J. Complement. Integr. Med. 2020. [CrossRef]

5. Mechchate, H.; Es-Safi, I.; Bourhia, M.; Kyrylchuk, A.; El Moussaoui, A.; Conte, R.; Ullah, R.; Ezzeldin, E.; Mostafa, G.A.; Grafov, A.; et al. In-Vivo Antidiabetic Activity and In-Silico Mode of Action of LC/MS-MS Identified Flavonoids in Oleaster Leaves. Molecules 2020, 25, 5073. [CrossRef] [PubMed]

6. Deans, S.G.; Svoboda, K.P. The antimicrobial properties of marjoram (Origanum majorana L.) volatile oil. Flavour Fragr. J. 1990, 5, 187-190. [CrossRef]

7. Jin Jun, W.; Kyung Han, B.; Won Yu, K.; Sung Kim, M.; Seop Chang, I.; Yun Kim, H.; Yon Cho, H. Antioxidant effects of Origanum majorana L. on superoxide anion radicals. Food Chem. 2001, 75, 439-444. [CrossRef]

8. Olfa, B.; Mariem, A.; Salah, A.M.; Mouhiba, B.A. Chemical content, antibacterial and antioxidant properties of essential oil extract from Tunisian Origanum majorana L. cultivated under saline condition. Pak. J. Pharm. Sci. 2016, 29, 1951-1958.

9. Bina, F.; Rahimi, R. Sweet Marjoram: A Review of Ethnopharmacology, Phytochemistry, and Biological Activities. J. Evid. Based Complement. Altern. Med. 2017, 22, 175-185. [CrossRef]

10. Al-Howiriny, T.; Alsheikh, A.; Alqasoumi, S.; Al-Yahya, M.; ElTahir, K.; Rafatullah, S. Protective Effect of Origanum majorana L. "Marjoram” on Various Models of Gastric Mucosal Injury in Rats. Am. J. Chin. Med. 2009, 37, 531-545. [CrossRef]

11. Abdel-Massih, R.M.; Fares, R.; Bazzi, S.; El-Chami, N.; Baydoun, E. The apoptotic and anti-proliferative activity of Origanum majorana extracts on human leukemic cell line. Leuk. Res. 2010, 34, 1052-1056. [CrossRef]

12. Münte, T.F.; Gehde, E.; Johannes, S.; Seewald, M.; Heinze, H.-J. Effects of Alprazolam and Bromazepam on Visual Search and Verbal Recognition Memory in Humans: A Study with Event-Related Brain Potentials. Neuropsychobiology 1996, 34, 49-56. [CrossRef] [PubMed]

13. Pae, C.-U.; Patkar, A.A. Paroxetine: Current status in psychiatry. Expert Rev. Neurother. 2007, 7, 107-120. [CrossRef] [PubMed]

14. Porsolt, R.D.; Bertin, A.; Jalfre, M. Behavioral despair in mice: A primary screening test for antidepressants. Arch. Int. Pharmacodyn. Ther. 1977, 229, 327-336.

15. Cryan, J.; Markou, A.; Lucki, I.; Cryan, J.F.; Markou, A.; Lucki, I. Assessing antidepressant activity in rodents: Recent developments and future needs. Trends Pharmacol. Sci. 2002, 23, 238-245. [CrossRef]

16. Rodríguez-Landa, J.F.; Cueto-Escobedo, J.; Flores-Aguilar, L.Á.; Rosas-Sánchez, G.U.; Rovirosa-Hernández, M.D.J.; García-Orduña, F.; Carro-Juarez, M. The Aqueous Crude Extracts of Montanoa frutescens and Montanoa grandiflora Reduce Immobility Faster Than Fluoxetine Through GABAA Receptors in Rats Forced to Swim. J. Evid. Based Integr. Med. 2018, 23, 2515690X18762953. [CrossRef]

17. Detke, M.J.; Lucki, I. Detection of serotonergic and noradrenergic antidepressants in the rat forced swimming test: The effects of water depth. Behav. Brain Res. 1996, 73, 43-46. [CrossRef]

18. Yan, B.; Wang, D.; Xing, D.; Ding, Y.; Wang, R.; Lei, F.; Du, L. The antidepressant effect of ethanol extract of radix puerariae in mice exposed to cerebral ischemia reperfusion. Pharmacol. Biochem. Behav. 2004, 78, 319-325. [CrossRef] [PubMed]

19. Maurmann, N.; Reolon, G.K.; Rech, S.B.; Fett-Neto, A.G.; Roesler, R. A Valepotriate Fraction of Valeriana glechomifolia Shows Sedative and Anxiolytic Properties and Impairs Recognition but Not Aversive Memory in Mice. Evid. Based Complement. Altern. Med. 2011, 2011. [CrossRef] [PubMed] 
20. Choleris, E.; Thomas, A.W.; Kavaliers, M.; Prato, F.S. A detailed ethological analysis of the mouse open field test: Effects of diazepam, chlordiazepoxide and an extremely low frequency pulsed magnetic field. Neurosci. Biobehav. Rev. 2001, 25, 235-260. [CrossRef]

21. Lazaros, C.; Triarhou, M. Dopaminergic Neuron Transplantation in the Weaver Mouse Model of Parkinson's; Springer: New York, NY, USA, 2012.

22. Walsh, R.N.; Cummins, R.A. The open-field test: A critical review. Psychol. Bull. 1976, 83, 482-504. [CrossRef] [PubMed]

23. Linck, V.M.; da Silva, A.L.; Figueiró, M.; Caramão, E.B.; Moreno, P.R.H.; Elisabetsky, E. Effects of inhaled Linalool in anxiety, social interaction and aggressive behavior in mice. Phytomed. Int. J. Phytother. Phytopharm. 2010, 17, 679-683. [CrossRef] [PubMed]

24. Doukkali, Z.; Kamal, R.; Jemelif, M.E.; Nadjmouddine, M.; Zellou, A.; Cherrah, Y.; Alaoui, K.; Taghzouti, K. Anti-Anxiety Effects of Mercurialis annua Aqueous Extract in the Elevated Plus Maze Test. Pharm. Bioprocess. 2016, 4, 56-61.

25. Walesiuk, A.; Braszko, J.J. Preventive action of Ginkgo biloba in stress- and corticosterone-induced impairment of spatial memory in rats. Phytomedicine 2009, 16, 40-46. [CrossRef] [PubMed]

26. Ennaceur, A. Tests of unconditioned anxiety-Pitfalls and disappointments. Physiol. Behav. 2014, 135, 55-71. [CrossRef]

27. Rezaie, A.; Jafari, B.; Mousavi, G.; Ebadi, A.R.; Ahmadizadeh, C.; Shishegar, R.; Pashazadeh, M. Study of anxiolytic effect of herbal extract of Origanum majorana L. in comparison with diazepam in rat. Iran. J. Med. Aromat. Plants 2014, 30, 134-141.

28. Willner, P. Validity, reliability and utility of the chronic mild stress model of depression: A 10-year review and evaluation. Psychopharmacology 1997, 134, 319-329. [CrossRef]

29. Li, G.; Ruan, L.; Chen, R.; Wang, R.; Xie, X.; Zhang, M.; Chen, L.; Yan, Q.; Reed, M.; Chen, J.; et al. Synergistic antidepressant-like effect of ferulic acid in combination with piperine: Involvement of monoaminergic system. Metab. Brain Dis. 2015, 30, 1505. [CrossRef]

30. Karković Marković, A.; Torić, J.; Barbarić, M.; Jakobušić Brala, C. Hydroxytyrosol, Tyrosol and Derivatives and Their Potential Effects on Human Health. Molecules 2019, 24, 2001. [CrossRef]

31. Freitas, J.G.; Fletcher, B.; Aravena, R.; Barker, J.F. Methane Production and Isotopic Fingerprinting in Ethanol Fuel Contaminated Sites. Groundwater 2010, 48, 844-857. [CrossRef]

32. Li, F.; Zaslavsky, A.M.; Landrum, M.B. Propensity score weighting with multilevel data. Stat. Med. 2013, 32, 3373-3387. [CrossRef] [PubMed]

Publisher's Note: MDPI stays neutral with regard to jurisdictional claims in published maps and institutional affiliations.

(C) 2020 by the authors. Licensee MDPI, Basel, Switzerland. This article is an open access article distributed under the terms and conditions of the Creative Commons Attribution (CC BY) license (http://creativecommons.org/licenses/by/4.0/). 